\title{
Reducing Your Risk for Heart Disease: The Power of Food $^{1}$
}

\author{
Elena B. Smith, Jodi Fitzgerald, Danielle Nelson, Madison Woodard, and Jeanette Andrade²
}

\section{Overview of Heart Disease}

Heart disease is the leading cause of death among men and women within the United States (Kochanek, Murphy, Xu, and Arias 2016).

Heart disease is an umbrella term for the following heart conditions:

- Angina

- Heart attacks

- Heart failure

- Irregular heartbeats

- Stroke

This publication describes the modifiable risk factors for heart disease and tips to reduce one's risk for heart disease.

\section{Risk Factors for Heart Disease}

Individuals may be at an increased risk for developing heart disease based on their age and genetics. Even though these factors cannot be changed, listed below are some risk factors that one can change (American Heart Association 2016).

\section{Weight}

Health professionals determine if one is at a healthy weight based on the Body Mass Index (BMI). BMI is calculated using your height and weight. People who are considered at a healthy BMI (18.5-24.9) have a lower risk for developing heart disease. Extra weight can lead to higher low-density lipoprotein (LDL) cholesterol levels and lower high-density lipoprotein (HDL) cholesterol levels, high blood pressure, and higher triglyceride levels (American Heart Association 2016).

\section{Blood Pressure}

High blood pressure happens when the pressure in one's arteries and other vessels in the body is too high. A health professional can diagnose if someone has this condition based on blood pressure readings. Further information about blood pressure can be found at https://www.nia.nih. gov/health/high-blood-pressure.

\section{Blood Cholesterol}

As certain blood cholesterol levels increase or decrease, one is at an increased risk for heart disease.

\section{LDL CHOLESTEROL}

If blood LDL cholesterol levels are too high, it will build up in the vessel walls to create plaque. A buildup of plaque

1. This document is FSHN20-56, one of a series of the Food Science and Human Nutrition Department, UF/IFAS Extension. Original publication date December 2020. Visit the EDIS website at https://edis.ifas.ufl.edu for the currently supported version of this publication.

2. Elena B. Smith, graduate student, Food Science and Human Nutrition Department; Jodi Fitzgerald, MD; Danielle Nelson, MD, MPH, assistant professor and assistant medical director, University of Florida Department of Community Health and Family Medicine; Madison Woodard, undergraduate student, Food Science and Human Nutrition Department; and Jeanette Andrade, assistant professor and director, MS-DI program, Food Science and Human Nutrition Department; UF/IFAS Extension, Gainesville, FL 32611.

The Institute of Food and Agricultural Sciences (IFAS) is an Equal Opportunity Institution authorized to provide research, educational information and other services

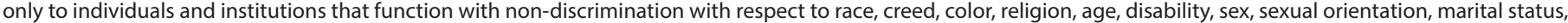

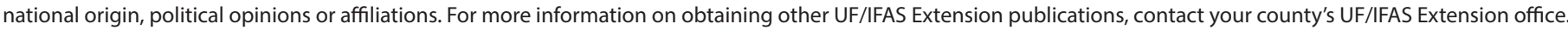
U.S. Department of Agriculture, UF/IFAS Extension Service, University of Florida, IFAS, Florida A \& M University Cooperative Extension Program, and Boards of County Commissioners Cooperating. Nick T. Place, dean for UF/IFAS Extension. 
in the blood vessels will lead to vessels narrowing, so less blood can flow through, which may lead to a heart attack. A diet that is high in saturated fat, such as fatty beef, lard and cream, and other high-fat dairy products, and that is low in fruits, vegetables, and whole grains increases this cholesterol (National Heart, Lung, and Blood Institute 2002). To read more about LDL cholesterol, please visit https://www. cdc.gov/cholesterol/ldl_hdl.htm.

\section{HDL CHOLESTEROL}

HDL cholesterol picks up cholesterol in the blood vessels and brings it to the liver. The liver then removes it from the body (CDC 2020). A diet that is high in fruits, vegetables, and whole grains helps to increase HDL levels, as does being physically active for at least 30 minutes daily for at least 5 days per week. To read more about HDL cholesterol, please visit https://www.cdc.gov/cholesterol/ldl_hdl.htm.

\section{Triglycerides}

Triglycerides are a type of fat that is found in foods and that can be made within your body. Genetics, lifestyle behaviors, and some medications may increase triglyceride levels. Additionally, a diet that is high in saturated fats, added sugars, and alcohol can increase one's triglyceride levels, as can limited physical activity (National Heart, Lung, and Blood Institute n.d.).

\section{Diabetes}

If one has diabetes and blood glucose (sugar) levels that are considered high, they are at a higher risk for developing heart disease. Talk with a health care professional to come up with a diet and exercise plan to improve your blood glucose levels.

\section{Dietary Habits}

Dietary habits may increase the risk for heart disease, specifically:

- High amounts of saturated fats (e.g., fatty red meats, chicken with the skin, butter, cheese)

- High amounts of salt (e.g., processed and cured meats, chips, crackers, sauces, dressings)

- Low amounts of fresh or frozen fruits, vegetables, and whole grains

\section{Lifestyle}

Certain lifestyle behaviors may increase the risk for heart disease, such as:

- Smoking: Tobacco, of all forms, even secondhand smoke

- Excess alcohol:

- For females: Drinking more than 1 alcoholic beverage per day

- For males: Drinking more than 2 alcoholic beverages per day

- Beverage amounts equal to one serving:

- 12 ounces of $5 \%$ alcohol by volume (ABV) beer

- 8 ounces of $7 \% \mathrm{ABV}$ malt liquor

- 5 ounces of $12 \%$ ABV wine

- 1.5 ounces of $40 \%$ ABV (80 proof) distilled spirits or liquor (USDA 2015).

- Physical inactivity: Not being physically active (walking, running, swimming, yoga) for at least 150 minutes per week

\section{Reducing the Risk for Heart Disease}

\section{Eat more fruits, vegetables, beans/lentils, and whole grains. These foods are:}

- High in vitamins, minerals, and antioxidants that help protect your heart.

- High in fiber.

- Low in saturated fat.

- Refer to Table 1: What and How Much to Eat below for further information.

\section{Lower Salt Intake}

- Per the American Heart Association guidelines, consume no more than 2,300 $\mathrm{mg}$ of sodium per day.

- Use onions, garlic, herbs, spices, citrus juices, and vinegars in place of sodium when preparing meals at home.

- Read the food labels for sodium content when purchasing packaged foods (USDA).

\section{Be Kind to You}

- Take some time for yourself every day, even if it just for 10 minutes!

- Sleep for at least 7 hours per day. 
- Stay active-exercise at least 30 minutes per day for at least 5 days per week.

- If you consume alcohol, drink no more than 1 drink/day for females and no more than 2 drinks/day for males.

Review the above information for specific amounts.

- Avoid use of and exposure to tobacco products.

- Reduce stress as much as you can.

\section{Setting Yourself Up for Success}

- Use the suggested recipes in this publication for inspiration for healthy eating.

- Start making changes with a friend or family member! It can be helpful to have support.

- Ask for help from a health professional such as a registered dietitian to make those positive changes.

\section{What and How Much to Eat}

Table 1. What and how much to eat.

\begin{tabular}{|c|c|c|c|}
\hline Food Group & $\begin{array}{l}\text { Amount and Type of Foods to } \\
\text { Consume }\end{array}$ & Focus on Consuming & Reasons \\
\hline Grains & $\begin{array}{l}6-8 \text { ounces } \\
1 \text { ounce }=1 \text { slice of bread; } 1 / 2 \text { cup } \\
\text { cooked pasta/rice; } 1 / 2 \text { cup cooked cereal }\end{array}$ & $\begin{array}{l}\text { - Whole grains: whole-wheat breads, } \\
\text { whole-wheat/buckwheat pasta, rolled } \\
\text { old-fashioned oats, brown rice, lentils, } \\
\text { amaranth, bulgur, quinoa, farrow, and } \\
\text { barley }\end{array}$ & $\begin{array}{l}\text { - Whole grains have more nutrients } \\
\text { and fiber than refined grains, such } \\
\text { as white bread, white rice, and white } \\
\text { pasta. }\end{array}$ \\
\hline Fruits & $\begin{array}{l}1.5-2 \text { cups } \\
1 \text { cup equivalent = } 1 \text { cup raw or cooked } \\
\text { fruit, } 1 / 2 \text { cup dried fruit }\end{array}$ & $\begin{array}{l}\text { - Fresh or frozen that are in season } \\
\text { - Variety of colorful fruits } \\
\text { - Less juice }\end{array}$ & $\begin{array}{l}\text { - Frozen fruits preserve nutrients. } \\
\text { - Different-colored fruits and } \\
\text { vegetables provide various vitamins, } \\
\text { minerals, and other nutrients that } \\
\text { you need. } \\
\text { - Juice does not have as much fiber } \\
\text { as the fresh/frozen fruit. }\end{array}$ \\
\hline Vegetables & $\begin{array}{l}2.5-3 \text { cups } \\
1 \text { cup equivalent = } 1 \text { cup raw or cooked } \\
\text { vegetable, } 2 \text { cups leafy salad greens }\end{array}$ & $\begin{array}{l}\text { - Variety of colorful vegetables that are } \\
\text { fresh or frozen and are in season }\end{array}$ & $\begin{array}{l}\text {-Frozen vegetables preserve the } \\
\text { nutrients. Save money by buying in } \\
\text { season. }\end{array}$ \\
\hline Dairy & $\begin{array}{l}3 \text { cups } \\
1 \text { cup equivalent = } 1 \text { cup milk, yogurt, } \\
\text { or fortified soymilk; } 1 \frac{112 \text { ounces natural }}{} \text { cheese such as cheddar cheese or } 2 \\
\text { ounces of processed cheese }\end{array}$ & $\begin{array}{l}\text { - Drink } 2 \% \text { or reduced fat milk and yogurt } \\
\text { and cheese. }\end{array}$ & $\begin{array}{l}\text { - Rich source of calcium and vitamin } \\
\text { D to help build strong bones. }\end{array}$ \\
\hline Protein & $\begin{array}{l}5 \text { to } 6.5 \text { ounces } \\
1 \text { ounce equivalent }=1 \text { ounce lean } \\
\text { meat, poultry, or seafood; } 1 \text { egg; } 1 / 4 \text { cup } \\
\text { cooked beans or tofu; } 1 \text { tbsp peanut } \\
\text { butter; } 1 / 2 \text { ounce nuts or seeds }\end{array}$ & $\begin{array}{l}\text { - Focus on eating lean meats, beans, } \\
\text { lentils, and soy. } \\
\text { - Bake, grill, or poach when cooking } \\
\text { meats. }\end{array}$ & $\begin{array}{l}\text { - Preparing lean meats through } \\
\text { baking, grilling, or poaching reduces } \\
\text { risk for heart disease. }\end{array}$ \\
\hline
\end{tabular}




\section{Breakfast Recipes}

\section{Greek Yogurt Fruit Bowl}

Recipe provided by MS/DI student Charissa Lim.

Prep time: 5 minutes

Cook time: 0 minutes

Makes 1 serving

\section{Ingredients}

- 1 cup $0 \%$ fat plain Greek yogurt

- $1 / 4$ cup strawberries

- $1 / 4$ cup frozen blueberries

- 2 tbsp granola

- 1 tbsp raisins

- 1 tsp honey

- $1 / 8$ tsp vanilla extract

\section{Instructions}

1. Place Greek yogurt in a bowl and mix in vanilla extract.

2. Add granola over half the yogurt bowl.

3. Slice strawberries and place on the other half along with the blueberries.

4. Drizzle honey on top and add raisins. Enjoy!

Nutrition Facts per Serving: 280 calories, $2.5 \mathrm{~g}$ total fat, $0 \mathrm{~g}$ saturated fat, $100 \mathrm{mg}$ sodium, $39 \mathrm{~g}$ total carbohydrates, $2 \mathrm{~g}$ dietary fiber

\section{4-Ingredient Breakfast Bars}

Recipe modified from The Kitchn: https://www.thekitchn. com/recipe-4-ingredient-banana-oat-bars-156571

Prep time: 10 minutes

Cook time: 30 minutes

Makes 6 Servings

\section{Ingredients}

- Cooking spray (for pan)

- 2 large, very ripe bananas-soft and covered with brown spots

- 2 cups old-fashioned oats

- $1 / 2$ cup whole flax seeds

- 1 tsp vanilla extract

\section{Optional Additions}

- $1 / 4$ cup pitted, chopped dried dates

- $1 / 2$ tsp nutmeg or cinnamon

- 1 tbsp brown sugar

\section{Instructions}

1. Heat oven to $350^{\circ} \mathrm{F}$.

2. Peel the bananas and mash them in a bowl.

3. Stir the oats, vanilla, flax seeds, and optional ingredients into the mix.

4. Pour into sprayed $9 " \times 9$ " baking pan and bake for 30 minutes.

5. When recipe is cool, cut into squares and enjoy!

Try making a few pans of this to store in your freezer for grab-and-go breakfast and snackbars!

Nutrition Facts per Serving: 240 calories, $8 \mathrm{~g}$ total fat, $1 \mathrm{~g}$ saturated fat, $0 \mathrm{mg}$ sodium, $35 \mathrm{~g}$ total carbohydrates, $8 \mathrm{~g}$ dietary fiber

\section{Egg-Vegetable Sandwich}

Recipe provided by author Jeanette.

Prep time: 5 minutes

Cook time: 6-7 minutes

Makes 1 serving

\section{Ingredients}

- Cooking spray

- 1 large egg, scrambled

- $1 / 4$ cup torn spinach leaves

- 1/4 cup coarsely chopped yellow onion

- 1 thin slice of tomato

- $1 / 8$ tsp Italian seasoning

- 1 100\% whole-wheat English muffin

\section{Instructions}

1.Scramble the egg with the Italian seasoning in a small bowl, and set aside.

2. Spray a small frying pan with the cooking spray. On medium-high heat, cook the onions until translucent, about 2-3 minutes.

3 . Add the egg mixture, stir the mixture, and cook until egg is set, about 2 minutes. Add in the spinach and cook for another 2 minutes. Remove from heat.

4. Cut the English muffin in half, add the tomato slice on one-half the muffin, and then add the scrambled egg mixture on top. Place the other half of the English muffin on top and enjoy!

Nutrition Facts per Serving: 220 calories, $5 \mathrm{~g}$ total fat, $1 \mathrm{~g}$ saturated fat, $330 \mathrm{mg}$ sodium, $30 \mathrm{~g}$ total carbohydrates, $2 \mathrm{~g}$ dietary fiber 


\section{Lunch/Dinner}

\section{Honey Chicken and Veggies}

Recipe modified from PureWow: https://www.purewow. com/recipes/honey-lime-chicken-in-foil

Prep time: 10 minutes

Cook time: $10-12$ minutes

Makes 4 servings

\section{Ingredients}

- 2 tbsp olive oil

- 2 garlic cloves, minced

- 2 tbsp honey

- 4 6-ounce skinless, boneless chicken breasts

- 1 tsp cumin

- $1 / 2$ tsp paprika

- $8 \mathrm{oz}$ frozen asparagus

- 4 half ears frozen corn

- 2 tbsp chopped cilantro

- $1 / 4$ cup sliced green onion

\section{Instructions}

1. Stir the olive oil, garlic, and honey in a bowl.

2. Place the chicken breasts on foil and season with cumin and paprika.

3. Add asparagus to the foil.

4. Brush the chicken and asparagus with the prepared sauce.

5. Grill (10 to 12 minutes).

6. Five minutes before done, add the corn to the grill, and cook until browned.

7. Garnish the chicken with cilantro and green onion.

Nutrition Facts per Serving: 340 calories, $10 \mathrm{~g}$ total fat, $1 \mathrm{~g}$ saturated fat, $125 \mathrm{mg}$ sodium, $22 \mathrm{~g}$ total carbohydrates, $1 \mathrm{~g}$ dietary fiber

\section{One-Pot Vegetable Pasta}

Recipe modified from recipetineats: https://www.recipetineats.com/vegetable-pasta/

Prep time: 15 minutes

Cook time: 25 minutes

Makes 4 servings

\section{Ingredients}

- 8 oz whole-wheat spaghetti

- 1 small zucchini, cut into medium-sized pieces

- 1/2 small eggplant, cut into medium-sized pieces

- 1 green bell pepper, cut into medium-sized chunks

- 1 red onion, chopped

- 2 tsp minced garlic (about 2 cloves)

- 1 cup cherry tomatoes, cut into halves

- 1 handful kale, roughly chopped
- 1 15-ounce can low-sodium black beans

- 3 cans low-sodium vegetable broth

- 1 tsp dried Italian seasoning

\section{Instructions}

1. Put all ingredients except for the kale into a large pot. Pour in the vegetable broth.

2. Season with Italian seasoning. Cook for about 3-4 minutes.

3. Add the kale and cook for an additional 9-11 minutes or until pasta is soft. Drain excess liquid and serve.

Nutrition Facts per Serving: 360 calories, $2.5 \mathrm{~g}$ total fat, $0 \mathrm{~g}$ saturated fat, $260 \mathrm{mg}$ sodium, $70 \mathrm{~g}$ total carbohydrates, $15 \mathrm{~g}$ dietary fiber

\section{Lemon-Garlic Salmon, Potato, and Green Bean Packs}

Recipe modified from the American Heart Association: https://recipes.heart.org/en/recipes/lemon-garlic-salmonfoil-pack-with-green-beans-and-new-potatoes

Prep time: 15 minutes

Cook time: 15 minutes

Makes 4 Servings

\section{Ingredients}

- Tinfoil-4 30" sheets

- $1 \mathrm{lb}$ new potatoes

- 4 tsp minced garlic (about 4 cloves)

- $12 \mathrm{oz}$ frozen green beans

- 2 tbsp olive oil

- $1 / 4$ teaspoon black pepper

- 4 4-ounce frozen skinless salmon filets

- 2 lemons, sliced thin (or use 2 tbsp lemon juice)

\section{Instructions}

1. Preheat oven to $400^{\circ} \mathrm{F}$. Fold tinfoil sheets in half so the packs will be sturdy.

2. Cut potatoes in half. Cut each half into thin slices and place in microwavable container. Stir in minced garlic, cover, and cook the potatoes in the microwave until slightly tender-around 90 seconds to 3 minutes.

3. Add green beans, oil, and pepper to potato bowl. Mix.

4. Divide green beans and potatoes onto the center of foil squares. Top each with a salmon filet. Add garlic and lemon to salmon.

5. Fold to seal the top and sides of packets. Place on baking sheet and bake for 20 minutes.

Nutrition Facts per Serving: 380 calories, $15 \mathrm{~g}$ total fat, 2 $\mathrm{g}$ saturated fat, $70 \mathrm{mg}$ sodium, $29 \mathrm{~g}$ total carbohydrates, $4 \mathrm{~g}$ dietary fiber 


\section{Dessert and Snack Recipe ideas}

\section{Avocado Dip}

Recipe retrieved from Pinch of Yum: https://pinchofyum. com/avocado-dip

Prep time: 5 minutes

Cook time: 0 minutes

Makes 2 servings

\section{Ingredients}

- 1/4 cup 0\% plain Greek yogurt

- 1 ripe avocado

- 1 lime

- $1 / 8$ tsp ground black pepper

\section{Preparation}

1. Cut avocado in half and remove pit.

2. Using a spoon, scoop the fruit out of the avocado into a large bowl. Add the avocado and mix in the pepper and yogurt. Once all blended, juice in the lime and stir until all blended. Serve with carrots or wheat crackers.

Nutrition Facts per Serving: 140 calories, $11 \mathrm{~g}$ total fat, 1.5 $\mathrm{g}$ saturated fat, $15 \mathrm{mg}$ sodium, $8 \mathrm{~g}$ total carbohydrates, $5 \mathrm{~g}$ dietary fiber

\section{Berry-Banana Oat Shake}

Recipe modified from Martha Stewart: https://www. marthastewart.com/341010/banana-oat-smoothie

Prep time: 5 minutes

Cook time: 0 minutes

Makes 2 servings

\section{Ingredients}

- $1 / 2$ cup cooked oatmeal using old-fashioned oats, chilled

- $2 / 3$ cup $2 \%$ milk

- 1 tbsp brown sugar

- 1.5 tsp vanilla extract

- $1 / 2$ cup frozen mixed berries

- 1 banana, cut into chunks

- 4 ice cubes

\section{Preparation}

1. Place oatmeal in a blender and blend for a few minutes.

2. Add the remaining ingredients and blend until thick and smooth.

Nutrition Facts per Serving: 190 calories, $2.5 \mathrm{~g}$ total fat, 1 g saturated fat, $45 \mathrm{mg}$ sodium, $36 \mathrm{~g}$ total carbohydrates, $4 \mathrm{~g}$ dietary fiber

\section{Peach-Berry Cobbler}

Recipe modified from Taste of Home: https://www.tasteofhome.com/recipes/peach-and-berry-cobbler/

Prep time: 20 minutes

Bake time: 40 minutes

Makes 8 servings

\section{Ingredients}

\section{Cobbler}

- $1 / 2$ cup sugar

- 3 tbsp cornstarch

- $1 / 2$ tsp ground cinnamon

- $1 / 4$ tsp ground cardamom

- 6 cups frozen peaches

- 2 cups frozen mixed berries

- 1 tbsp lemon juice

\section{Topping}

- 1 cup all-purpose flour

- $1 / 4$ cup sugar

- $3 / 4$ tsp baking powder

- $1 / 4$ tsp baking soda

- 3 tbsp cold unsalted butter

- 1 cup $0 \%$ plain Greek yogurt

\section{Preparation}

1. Preheat oven to $375^{\circ} \mathrm{F}$. In a large bowl, mix sugar, cornstarch, cinnamon, and cardamom. Add peaches, berries, and lemon juice; toss to combine. Transfer to a 10-inch ovenproof skillet.

2. In a small bowl, whisk the first 4 topping ingredients; cut in butter until mixture resembles coarse crumbs. Add yogurt; stir just until moistened. Drop mixture by tablespoonfuls over peach mixture.

3. Bake uncovered until topping is golden brown, 40-45 minutes. Serve warm.

Nutrition Facts per Serving: 290 calories, $5 \mathrm{~g}$ total fat, $2 \mathrm{~g}$ saturated fat, $290 \mathrm{mg}$ sodium, $56 \mathrm{~g}$ total carbohydrates, $2 \mathrm{~g}$ dietary fiber 
Grocery Shopping for Heart-Healthy Recipes

Fresh/Frozen Foods

Avocado

Bananas

Cherry tomatoes

Chicken breasts, skinless, boneless

Cilantro

Egg

Eggplant

Frozen asparagus

Frozen blueberries

Frozen corn on the cob

Frozen green beans

Frozen mixed berries

Frozen peaches

Garlic cloves

$0 \%$ fat plain Greek yogurt

Green bell pepper

Green onion

Kale

Lemons (or sub lemon juice)

$\square$ Lime (or sub lime juice)

$\square$ New potatoes

$\square 2 \%$ milk

$\square$ Red onion

Salmon filets

Spinach

Strawberries

Tomatoes

$\square$ Yellow onion

Zucchini
Bottled/Canned/Dry Goods Pantry Items

$\square$ Brown sugar, light

Cardamom

Canned no-salt-added or lowsodium black beans

100\% whole-wheat English muffin

$\square$ Flax seeds

$\square$ Granola

$\square$ Honey

$\square$ Low-sodium vegetable broth

$\square$ Olive oil

$\square$ Raisins

Rolled oats

$\square$ Whole-wheat spaghetti
Cinnamon

Cooking spray

Cornstarch

Cumin

Garlic powder

Ground black pepper

Ground ginger

Italian seasoning

Paprika

Vanilla extract

Find more healthy and delicious recipes at these websites:

American Heart Association: https://recipes.heart.org

MyPlate Recipe Guides: https://www.myplate.gov/myplate-kitchen/recipes 


\section{References}

American Heart Association. 2016. "Understand Your Risks to Prevent Heart Disease." Retrieved January 11, 2020. https://www.heart.org/en/health-topics/heart-attack/ understand-your-risks-to-prevent-a-heart-attack

Centers for Disease Control. 2020. "LDL and HDL Cholesterol: 'Bad' and 'Good' Cholesterol.” Retrieved June 10, 2020. https://www.cdc.gov/cholesterol/ldl_hdl.htm

Kochanek, K. D., S. L. Murphy, J. Q. Xu, and E. Arias. 2017. Mortality in the United States, 2016. NCHS Data Brief, no 293. Hyattsville, MD: National Center for Health Statistics.

National Heart, Lung, and Blood Institute. 2002. "Adopting Healthful Lifestyle Habits to Lower LDL Cholesterol and Reduce CHD Risk." Circulation 106 (25): 3147-3373.

National Heart, Lung, and Blood Institute. n.d. "High Blood Triglycerides." Retrieved March 17, 2020. https://www. nhlbi.nih.gov/health-topics/high-blood-triglycerides

US Department of Agriculture. 2020. "Sodium in Your Diet: Use the Nutrition Facts Label and Reduce Your Sodium Intake." Retrieved June 14, 2020. https://www.fda.gov/food/ nutrition-education-resources-materials/sodium-your-diet

US Department of Health and Human Services and US Department of Agriculture. 2015. 2015-2020 Dietary Guidelines for Americans. 8th Edition. https://health.gov/our-work/ food-and-nutrition/2015-2020-dietary-guidelines/ 